\title{
Occurrence of natural infection of tomato by Potato Spindle Tuber Viroid (PSTVd) in India
}

\author{
Shilpa Natarajamurthy ${ }^{1,2} \cdot$ Sumashri Kepu Shankaranarayana Bhat ${ }^{1} \cdot$ Janardhana Gottravalli Ramanayaka $^{1}$
}

Received: 31 May 2021 / Accepted: 27 July 2021 / Published online: 2 August 2021

(c) Australasian Plant Pathology Society Inc. 2021

\begin{abstract}
A field survey was carried out in districts of southern Karnataka to assess the pospiviroid infections on tomato crop. The tomato plants showing disease symptoms such as severe leaf curling, epinasty, chlorosis, purpling and stunted growth that are characteristics of viroid infection were collected along with asymptomatic plants and the infection was analysed by RTPCR. A sample collected from the Mandya district showed an amplicon size of $\sim 361 \mathrm{bp}$ which confirmed PSTVd infection, while no other Pospiviroids were detected. The amplified PCR products were cloned, sequenced and the resultant sequences were deposited in GenBank. The PSTVd sample inoculated tomato plants also showed typical disease symptoms of viroid infection after four weeks of post-inoculation and was re-confirmed through RT-PCR. This is the first report of the occurrence of natural infection of tomato by PSTVd in India.
\end{abstract}

Keywords Bioassay $\cdot$ Pospiviroids $\cdot$ Potato spindle tuber viroid $\cdot \mathrm{RT}-\mathrm{PCR}$

Potato spindle tuber viroid (PSTVd) is a non-coding infectious RNA molecule known to cause serious diseases in potato and tomato crops. Tomato (Solanum lycopersicum L.; Family-Solanaceae) is one of the most important vegetable crops grown for its edible berries. In India, the tomato is being cultivated as rain-fed and irrigated crop. Throughout 2017-18, 789,000 hectares of land was under tomato cultivation with an annual production of 19,759 Metric tonnes (Anonymous 2018). In the recent past, the crop yield has been seriously affected by both biotic and abiotic factors. During 2017 to 2019, a field survey was carried out to detect the presence of PSTVd in 37 tomato crop-growing fields each measuring $0.5-1$ acre covering an area of approximately 25-30 acres. The areas include Mysore, Mandya, Chamarajanagara, Hassan and Bangalore Rural districts of Karnataka state (India) (Suppl. Table 1). All the symptomatic tomato plants (83) showing severe leaf

Janardhana Gottravalli Ramanayaka grjbelur@gmail.com

1 Molecular Phytodiagnostic Laboratory, Department of Studies in Botany, University of Mysore, Manasagangotri, Mysuru, Karnataka 570 006, India

2 Department of Studies in Microbiology, University of Mysore, Manasagangotri, Mysuru 570 006, Karnataka, India curling, epinasty, chlorosis, purpling and stunted growth that are characteristics of viroid infection were collected along with two asymptomatic plants from each field for further analysis (Fig. 1).

The total RNA was extracted from the collected samples using $2 \mathrm{X}$ CTAB buffer, followed by $4 \mathrm{M}$ Lithium chloride precipitation to enrich low molecular weight RNAs (Adkar-Purushothama et al. 2011). A two-step reverse transcription-polymerase chain reaction (RT-PCR) was performed to confirm the presence of viroid using universal primer pair Pospi1-FW/ Pospi1-RE (Verhoeven et al. 2004) and the asymptomatic tomato plants served as a negative control. Among the 83 screened samples, a sample from Banaghatta $\left(12^{\circ} 31^{\prime} 37.7^{\prime \prime} \mathrm{N} 76^{\circ} 40^{\prime} 05.5^{\prime \prime} \mathrm{E}\right)$, Mandya district, sampled during 2019, showed an expected amplicon size of $\sim 200 \mathrm{bp}$, while others did not. The amplified PCR product was sequenced directly and analyzed through BLASTn, which revealed the association of PSTVd. Further, a full-length viroid genome ( $361 \mathrm{bp})$ was amplified using a specific set of primers $3 \mathrm{H} 1 / 2 \mathrm{H} 1$ for PSTVd (Shamloul et al. 1997), purified, cloned into pGEM®-T Easy vector (Promega, Madison, USA) and sequenced. The pathogenicity of the isolated viroid sample was tested on six 15-days old tomato seedlings (cv. Rutgers) at the two-leaf stage. Briefly, two leaves of each seedling were dusted with carborundum and $20 \mu \mathrm{l}$ of 
Fig. 1 Asymptomatic (A) and PSTVd infected (B) tomato plant showing stunted growth, leaf curling, epinasty and purpling on leaves
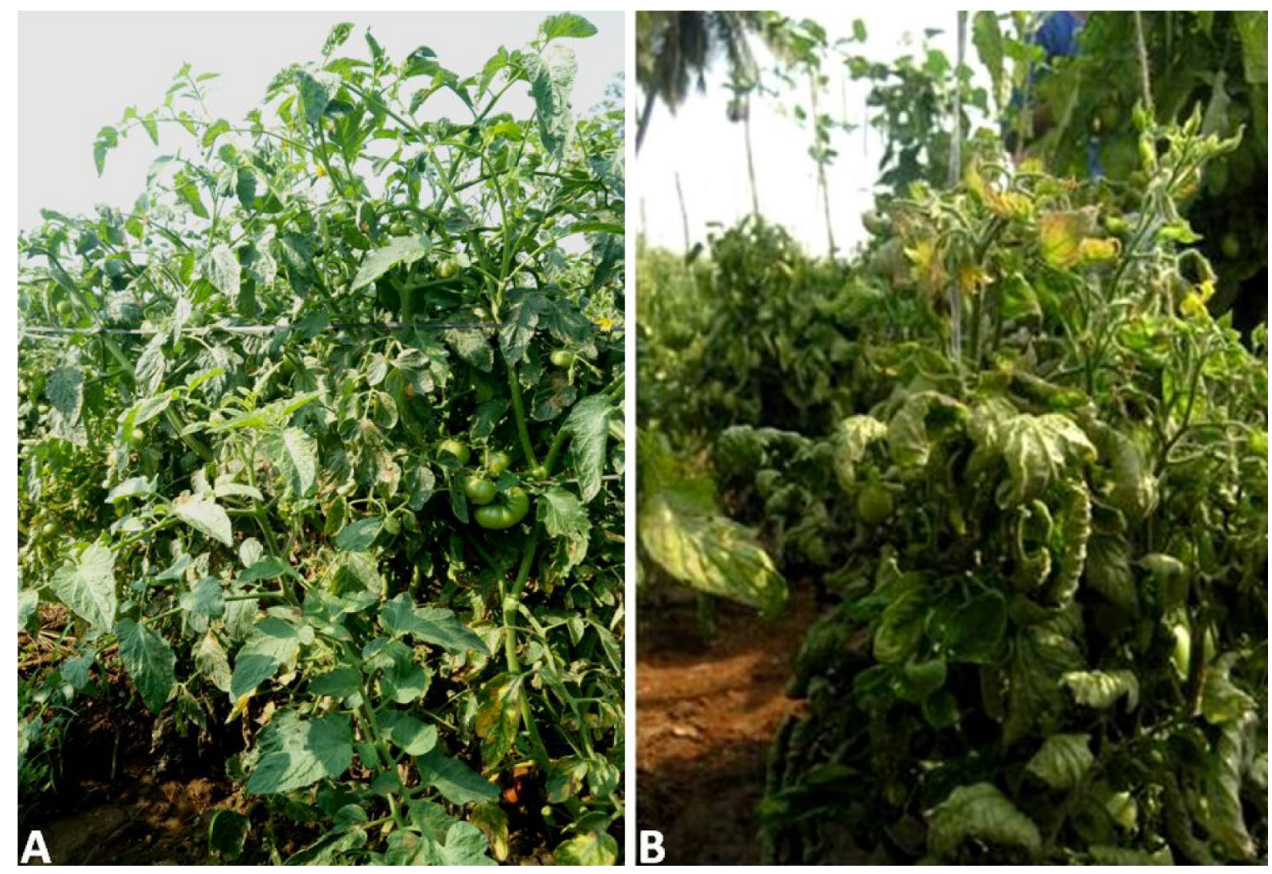

viroid RNA prepared in 0.5 M phosphate buffer (pH-7.0) was gently rubbed onto the upper surface of the leaves and rinsed gently with distilled water. The inoculated seedlings were maintained in a greenhouse $\left(25 \pm 2{ }^{\circ} \mathrm{C}\right)$ along with three mock-inoculated (control) plants (Sano et al. 2004). The experiment was repeated twice. Four weeks after post-inoculation, typical symptoms of PSTVd such as leaf curling, chlorosis and stunted growth were observed only in sap inoculated seedlings. Further, PSTVd infection in the symptomatic plants were re-confimred by RT-PCR

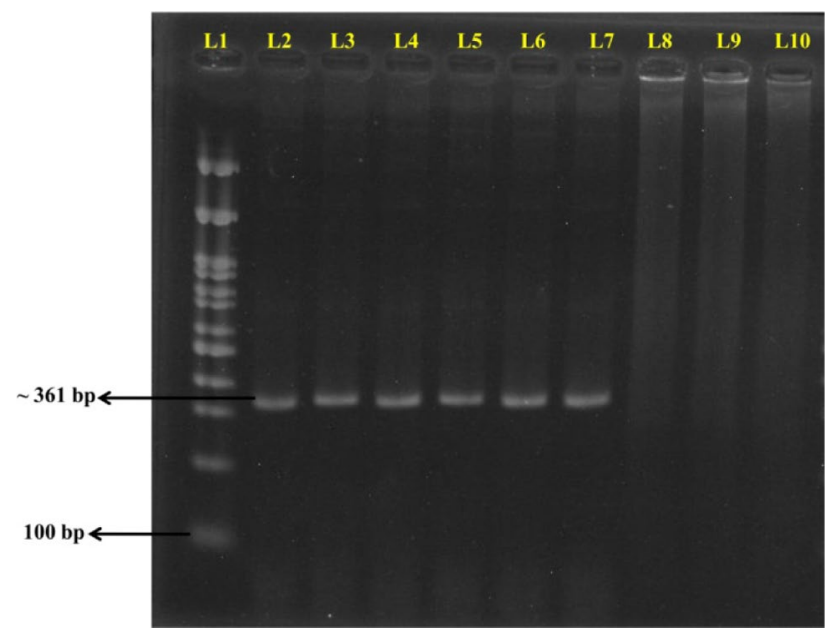

Fig. 2 A 2\% Agarose gel showing amplification for the PSTVd viroids in bioassay. L1-100 bp ladder, L2-L7 represent amplification of six challenge inoculated plants showing expected amplicon size ( 361 bp) for PSTVd and L8-L10 represent mock inoculated control plants and the presence of PSTVd was confirmed by RT-PCR
(Fig. 2) and sequenced. The two representative full-length sequences i.e. one from cloned product and other from bioassayed plant were deposited in NCBI GenBank with Accession No. MW114500 and MW114501, respectively. The PSTVd infection in tomato have been reported from many countries, including Australia (Hailstones et al. 2003), Belgium (Verhoeven et al. 2007), Ghana and Mali (Batuman et al. 2019), Italy (Navarro et al. 2009), New Zealand (Elliott et al. 2001), Turkey (Bostan et al. 2010), UK (Mumford et al. 2004) and the USA (Ling and Sfetu 2010). The nucleotide sequence analysis showed $97.10 \%$ similarity with PSTVd infecting potato in India (Accession No. MH758760), 96.63\% similarity with PSTVd infecting potato in Russia (Accession No. JQ889847), 96.36\% identity with China (Accession No. KR611357) along with $95.79 \%$ similarity with Indian isolate (Accession No. HQ639700). In India PSTVd is under strict quarantine and phytosanitary regulations of the Ministry of Agriculture and Farmers Welfare, Govt. of India, as it has been found to infect potato plants. Eventhough the inoculums exact source is unknown in the present study, it could have been infected from the other solanaceous crops including tomato seeds, as reported by earlier studies (Verhoeven et al. 2010). PSTVd infection has also been detected from the seeds of uncultivated Solanum species such as Solanum anguivi, S. coagulans and S. dasyphyllum collected from Ghana, Kenya and Uganda (Skelton et al. 2019). PSTVd infection could also be possible from the germplasm of the potato as reported by Roy et al. (2017) in India. Hence further investigation is needed to identify the source of viroid infection as it may threaten tomato and 
other agriculturally important crops in India. To the best of our knowledge, this is the first report of natural infection of PSTVd in tomato crop in India.

Supplementary Information The online version contains supplementary material available at https://doi.org/10.1007/s13314-021-00432-0.

Acknowledgements The authors acknowledge the help rendered by Prof. Teruo Sano, Faculty of Agriculture and Life Science, Hirosaki University, Department of Plant Pathology, Hirosaki, Aomori, Japan, for providing tomato seeds ( $\mathrm{Cv}$. Rutgers) for conducting bioassay and his valuable suggestions during the course of investigation.

Funding The authors would like to thank DST-SERB, Govt. of India, New Delhi for providing funds (SB/EMEQ-135/2013 dated 11/10/2013) and the University of Mysore for providing fellowship for the first author (Uni. Order No. ViGha 03/06/2017-18 Dated: 03/10/2017).

\section{References}

Adkar-Purushothama CR, Maheshwar PK, Sano T, Janardhana GR (2011) A sensitive and reliable RT-nested PCR assay for detection of Citrus tristeza virus from naturally infected citrus plants. CurrMicrobiol 62(5):1455-1459. https://doi.org/10.1007/ s00284-011-9883-7

Anonymous (2018) Horticultural Statistics at a Glance 2018. National Horticulture Board, Ministry of Agriculture and Farmers Welfare, Government of India, p 10

Batuman O, Ciftci OC, Osei MK, Miller SA, Rojas MR, Gilbertson RL (2019) Rasta disease of tomato in Ghana is caused by the Pospiviroids Potato spindle tuber viroid and Tomato apical stunt viroid. Plant Dis 103(7):1525-1535. https://doi.org/10.1094/ PDIS-10-18-1751-RE

Bostan H, Gazel M, Elibuyuk IO (2010) Occurrence of Pospiviroid in potato, tomato and some ornamental plants in Turkey. Afr $\mathbf{J}$ Biotechnol 9(18):2613-2617

Elliott DR, Alexander BJR, Smales TE, Tang Z, Clover GRG (2001) First report of Potato spindle tuber viroid in Tomato in New Zealand. Plant Dis 85(9):1027-1027. https://doi.org/10.1094/PDIS. 2001.85.9.1027B

Hailstones DL, Tesoriero LA, Terras MA, Dephoff C (2003) Detection and eradication of Potato spindle tuber viroid in tomatoes in commercial production in New South Wales. Australia Australas Plant Pathol 32(2):317-318. https://doi.org/10.1071/AP03005

Ling KS, Sfetcu D (2010) First report of natural infection of greenhouse tomatoes by Potato spindle tuber viroid in the United States. Plant Dis 94(11):1376-1376. https://doi.org/10.1094/PDIS-07-10-0516

Mumford RA, Jarvis B, Skelton A (2004) The first report of potato spindle tuber viroid (PSTVd) in commercial tomatoes in the UK. Plant Pathol 53(2):242. https://doi.org/10.1111/j.0032-0862.2004. 00995.x

Navarro B, Silletti MR, Trisciuzzi VN, Di Serio F (2009) Identification and characterization of Potato spindle tuber viroid infecting tomato in Italy. J Plant Pathol 91(3):723-726. https://doi.org/10. 4454/jpp.v91i3.569

Roy A, Kumar A, Walia Y, Hallan V, Ramachandran P (2017) Studies on Viroids Occurring in India. In A Century of Plant Virology in India. Springer, Singapore, p 487-511. https://doi.org/10.1007/ 978-981-10-5672-7_22

Sano T, Yoshida H, Goshono M, Monma T, Kawasaki H, Ishizaki K (2004) Characterization of a new viroid strain from hops: evidence for viroid speciation by isolation in different host species. J Gen Plant Pathol 70:181-187. https://doi.org/10.1007/ s10327-004-0105-Z

Shamloul AM, Hadidi A, Zhu SF, Singh RP, Sagredo B (1997) Sensitive detection of potato spindle tuber viroid using RT-PCR and identification of a viroid variant naturally infecting pepino plants. Can J Pl Pathol 19(1):89-96. https://doi.org/10.1080/07060669709500580

Skelton A, Buxton-Kirk A, Fowkes A, Harju V, Forde S, Ward R, Fox A (2019) Potato spindle tuber viroid detected in seed of uncultivated Solanumanguivi, S. coagulans and S. dasyphyllum collected from Ghana, Kenya and Uganda. New Dis Rep 39:23-23. https:// doi.org/10.5197/j.2044-0588.2019.039.023

Verhoeven JTJ, Jansen CCC, Botermans M, Roenhorst JW (2010) Epidemiological evidence that vegetatively propagated, solanaceous plant species act as sources of Potato spindle tuber viroid inoculum for tomato. Pl Pathol 59:3-12. https://doi.org/10.1111/j. 1365-3059.2009.02173.x

Verhoeven JTJ, Jansen CCC, Roenhorst JW, Steyer S, Michelante D (2007) First report of Potato spindle tuber viroid in tomato in Belgium. Plant Dis 91(8):1055-1055. https://doi.org/10.1094/ PDIS-91-8-1055A

Verhoeven JTJ, Jansen CCC, Willemen TM, Kox LFF, Owens RA, Roenhorst JW (2004) Natural infections of tomato by Citrus exocortis viroid, Columnea latent viroid, Potato spindle tuber viroid and Tomato chlorotic dwarf viroid. Eur J Pl Pathol 110(8):823831. https://doi.org/10.1007/s10658-004-2493-5 